\title{
FOTOGRAFAR E NARRAR: A PRODUÇÃO DO CONHECIMENTO NO CONTEXTO DA ESCOLA
}

\author{
SOLANGE JOBIM E SOUZA \\ Programa de Pós-graduação em Psicologia \\ Clínica do Departamento de Psicologia da PUC-Rio \\ Faculdade de Educação da Universidade Federal do Rio de Janeiro \\ soljobim@psi.puc-rio.br
}

ANA ELISABETE LOPES

Doutoranda do Programa de Pós-graduação em Psicologia Clínica do Departamento de

Psicologia da PUC-Rio. Professora da rede municipal de ensino no Rio de Janeiro

analopes@unisys.com.br

\begin{abstract}
RESUMO
Este texto visa apresentar os resultados de pesquisa-intervenção que vem sendo realizada em uma escola que atende a portadores de necessidades especiais na rede municipal de ensino básico da cidade do Rio de Janeiro, em que os jovens utilizam-se da imagem fotográfica para interagir de modo crítico com o cotidiano. Portanto, tendo por base a produção livre de imagens fotográficas, os jovens criam narrativas que integram imagens e textos orais e escritos com o objetivo de construir uma consciência crítica do contexto escolar, compartilhada entre alunos e professores. Esta proposta de trabalho possibilitou-nos uma outra forma de aproximação da realidade escolar, que se dá a partir do olhar e das narrativas constituídas pelos próprios alunos. O diálogo desencadeado no processo de produção e leitura das fotografias revela características que aproximam e distinguem o contexto das escolas, especial e regular, e abre-nos uma perspectiva crítica e sensível de observação e análise sobre a escola, o processo de ensino-aprendizado e de inclusão social. ESCOLAS MUNICIPAIS - ENSINO BÁSICO - ENSINO DE $1^{\circ}$ GRAU - FOTOGRAFIAS EDUCAÇÃO ESPECIAL
\end{abstract}




\begin{abstract}
The aim of this paper is to present the results of an intervention research carried on in a public school for students with special needs in the city of Rio de Janeiro. In this school the youth make use of the photography in order to interact with their daily routine. On the basis of the photographic images created by them, the youth construct narratives showing a critical view of school environment. This research favoured a non conventional approach of the school, based upon the narratives and views produced by the students. Actually a dialogue was engaged through the process of production and interpretation of the photographs, and this dialogue showed singular features to the special schools but also showed features shared by special and regular schools and propitiated a sensitive and critical analysis about the social interaction and the learning process.
\end{abstract}

PUBLIC SCHOOLS - BASIC EDUCATION - PHOTOGRAPHY - SPECIAL EDUCATION

O que é olhar o mundo através das lentes? Que mudanças são desencadeadas no olhar através da mediação proporcionada pelos instrumentos técnicos? O que somos capazes de ver e o que nos escapa ao olhar? Conhecer o mundo através das lentes é criar um outro mundo possível? Quais as conseqüências dos usos destes aparatos nos modos de ser, agir e conhecer? De que modo podemos tirar partido do uso da tecnologia para construirmos um conhecimento crítico do cotidiano?

Estas questões hoje são feitas porque a cada dia sentimos com maior evidência o modo como a tecnologia da imagem se transformou numa prótese do olhar, sendo praticamente impossível falar da nossa existência no mundo atual sem os aparatos técnicos que acabaram por modificar a própria natureza humana.

Podemos considerar que depois da invenção do ato de fotografar a experiência humana nunca mais foi a mesma, pois conquistamos, a partir dessa prótese da visão, um olhar sobre a materialidade do mundo físico e social que antes não era possível, criando em nós uma nova consciência cultural e subjetiva do mundo. De fato, com a fotografia iniciamos um longo caminho na construção de novos modos de escrita do mundo. Do mesmo modo que a escrita ortográfica revelou uma maneira mais sistemática e conceitual de tomarmos consciência da nossa cultura, a "foto-grafia" se constitui uma escrita atual do homem, mediada por tecnologia criadora de uma narrativa figurada. Além disso, podemos afirmar que as imagens constituem hoje as narrativas do mundo contemporâneo, trazendo novos elementos para buscarmos uma compreensão mais abrangente do próprio conceito de narrativa. Com isso a compreensão do que é hoje o domínio da leitura e da escrita mudou radicalmente, desafiando a escola a penetrar no universo dos signos que 
permeiam a experiência das crianças, dos jovens e adultos a partir da criação de novos códigos de interpretação e construção de sentidos.

Este texto visa apresentar os resultados de pesquisa-intervenção que vem sendo realizada em uma escola especial da rede municipal de ensino básico da cidade do Rio de Janeiro', em que os jovens se utilizam da imagem fotográfica para interagir de modo crítico com o cotidiano. Portanto, tendo por base a produção livre de imagens fotográficas, os jovens criam narrativas que integram imagens, textos orais e escritos com o objetivo de construir uma consciência crítica do contexto escolar, compartilhada entre alunos e professores. Antes, porém, de apresentar a análise dos resultados desta pesquisa-intervenção, alguns esclarecimentos conceituais se fazem necessários para justificar a dimensão política e cultural de tal abordagem metodológica no panorama atual da pesquisa em ciências humanas.

\section{A DIMENSÃO POLÍTICO-CULTURAL DA FOTOGRAFIA NO CONTEXTO EDUCACIONAL}

A experiência atual com as imagens, quer sejam fotográficas, cinematográficas ou televisivas, acontece na maioria das vezes de forma espontânea, intermitente, fragmentada, enfim, de modo superficial. Com a proliferação das imagens, a cada dia elas perdem mais a sua capacidade de dizer algo a alguém, pois também as pessoas que vivem essa dispersão perceptiva de modo permanente acabam por perder a sensibilidade para ver as coisas, enxergando-as como signos, extraindo sentidos diferenciados da materialidade do mundo e dos significados incorporados às imagens que nos rodeiam. Portanto, a leitura de imagens como uma atividade subjetiva, compromissada com a experiência racional e sensível de tomada de consciência do mundo, deve ser uma conquista e, assim, exige uma educação estética do olhar. Mas o que seria uma educação estética?

A educação estética leva a pensar sobre as contribuições da arte no processo educativo. A arte é uma produção social e um campo de conhecimento específico

I. Este projeto foi iniciado numa escola regular da rede municipal de ensino do Rio de Janeiro em 1998 com o nome de Oficina do Olhar. Para maiores informações, ver Sander (2002). De junho de 1999 a junho de 200 I, o projeto passou a ser realizado numa escola de educação especial da rede pública do Rio de Janeiro, sob a coordenação de Ana Elisabete Lopes e Luciana Sander. Para maiores informações sobre esta etapa do projeto ver Lopes; Sander; Souza (2000). Atualmente o projeto é coordenado pela pesquisadora Ana Elisabete Lopes, em parceria com a equipe da escola. 
que pode revelar outros modos de ver e compreender a realidade. Sua presença no contexto educacional vem contribuir para ampliar as possibilidades de interação do educando e do educador com esse campo que envolve a produção e a fruição estética/artística.

Na tensão estabelecida entre o convívio de diferentes pontos de vista e modos de ver encontramos a riqueza da experiência estética compartilhada. A educação estética tem como objetivo desvelar, ampliar e propor desafios a partir de experiências lúdicas, cognitivas e sensíveis que envolvam a arte e os demais campos do saber. $\bigcirc$ educador exerce um importante papel de mediador dessa experiência estética, ao procurar ampliar o contato mais crítico do educando com as formas e linguagens artísticas. Pode, assim, contribuir também para o enriquecimento do seu universo de experiências e de uma melhor compreensão da arte e da produção estética.

A escola se apresenta como um espaço no qual é possível propiciar o convívio e o diálogo entre o acervo de imagens pessoais, trazido pelos educadores e educandos, e as produções artísticas e culturais reconhecidas universalmente e pertencentes a diferentes culturas e épocas. Este exercício de ver o diferente, de desvelar significados e critérios exige um trabalho continuado de educação do olhar que articule percepção, imaginação, conhecimento, produção artística e, ao mesmo tempo, valorize e respeite a multiplicidade e a diversidade de pontos de vista, dos modos de ver e de estar no mundo.

A educação estética do olhar é aquela que incentiva o educando a intervir no ritmo dispersivo e intermitente que, em geral, estamos acostumados a exercitar quando interagimos com as imagens no cotidiano (TV, vídeo, cinema, fotografia, outdoors, computador etc.). É preciso aprender a olhar o mundo indo aos detaIhes, melhor dizendo, decompor o mosaico para melhor enxergar a figura que reina majestosa no todo de uma revelação figurativa. Nesse exercício que propomos com as imagens, a palavra é companheira, uma vez que com ela a imagem se enriquece, ganha contornos, torna-se icástica. Por mais que o mundo esteja se revelando aos nossos olhos através de narrativas figuradas, há que se decompor essas imagem em palavras e devolver ao outro as possíveis interpretações daquilo que é visto, tornando as imagens técnicas mediadoras de um diálogo entre pessoas que buscam novos modos de narrar sua experiência, recriando o mundo na imagem e no discurso. Torna-se, portanto, necessário criar sentidos novos com as imagens, criar composições que alteram e libertam nossa percepção do mundo em variadas direções. Aprender a ver o mundo com outros olhares, resgatando sua 
condição de diversidade, é formar leitores de imagens que sabem dar um sentido estético e ético ao modo como produzimos conhecimento na contemporaneidade. Este é um dos maiores desafios para a educação nos dias atuais.

Mas se a produção do conhecimento hoje não dispensa a nossa capacidade de dialogar com os aparatos tecnológicos, cabe tanto ao educador quanto aos jovens aprendizes construir, com esses aparatos tecnológicos, novas possibilidades de usos, submetendo as máquinas ao nosso poder e desejo de inventar outros jogos ainda não revelados na prática. Trata-se, portanto, de criarmos, por meio da educação, modos de confronto com a experiência tecnológica, colocando tanto educadores como educandos na posição de se sentirem responsáveis por inventar outras estratégias de interação na produção de conhecimento. Isso significa dizer que a educação mediada pela tecnologia é um jogo, pois cada vez mais as máquinas se transformam em aparatos para recuperarmos a dimensão lúdica na produção do conhecimento, que é de fato também trabalho. A relação jogo e trabalho no contexto da tecnologia transforma-se de modo radical. Como diz Flusser (1998), os instrumentos técnicos emancipam o homem do trabalho, libertando-o para o jogo. E, para reforçar o argumento nessa direção, é interessante observarmos como as crianças e os jovens lidam com os aparelhos. Se comparamos os adultos e as crianças nessas atividades, constatamos, com freqüência, um modo muito mais descontraído e familiar das crianças com as máquinas do que muitos adultos alcançam em situações similares. A criança não teme a tecnologia porque para ela, desde o princípio, os aparelhos são máquinas de jogar, são brinquedos. No brincar a criança inventa o jogo, cria sempre novos lances e desafia a máquina, experimentando com ousadia e curiosidade os resultados que desencadeia. Já o adulto não consegue a mesma descontração porque a máquina, tomada como mediadora do trabalho sério, perde todo o encantamento e a magia que a criança é capaz de alcançar. A criança está livre do sentido sério e sisudo que as coisas posteriormente adquirem no curso da vida e, por isso, pode nos mostrar novas alternativas de convívio com as máquinas. Cabe ao educador aprender essa postura com a criança e construir junto com ela, sem deixar de lado a sua experiência como adulto que vê o mundo de uma determinada maneira, modos mais criativos para enfrentar os desafios que a tecnologia nos impõe. $\bigcirc$ confronto entre gerações amplia o campo das experiências criadoras. O saber da criança, em contato com o conhecimento do adulto, é um campo fértil para descobertas que podem acontecer em um clima de autêntica liberdade, privilegiando os modos de ser, agir e conhecer de cada um.

Nossa proposta é criar as condições para que o uso da tecnologia no contex- 
to escolar possa favorecer a construção de estratégias de interação com o mundo físico e social que sejam promotoras de um certo modo de ver as coisas, interpretando e recriando o mundo de muitas e diferentes maneiras. Isso significa assumir o compromisso de desencadear um conhecimento que desmascare a superficialidade e a padronização do olhar, permitindo um mais profundo contato com a leitura e a interpretação das imagens que circulam entre nós.

\section{O OLHAR, A PALAVRA E UMA NOVA MEDIAÇÃO - A CÂMARA FOTOGRÁFICA}

A compreensão que o sujeito tem de si se constitui através do olhar e da palavra do outro. Cada um de nós ocupa um lugar determinado no espaço e desse lugar único revelamos o nosso modo de ver o outro e o mundo físico que nos envolve. Nessa perspectiva de análise, a ênfase está no lugar ocupado pelo olhar e pela palavra na constituição do sentido que conferimos à nossa experiência de estar no mundo. Uma dada pessoa, do seu ângulo de visão, pode mediar, com o seu olhar, aquilo que em mim não pode ser visto por mim. Portanto, a construção da consciência de si é fruto do modo como compartilhamos nosso olhar com o olhar do outro, criando, dessa forma, uma linguagem que permite decifrar mutuamente a consciência de si e do outro no contexto das relações socioculturais. Essa dimensão de alteridade vivida pelo sujeito no âmbito das interações sociais serve como um espelho daquilo que em mim se esconde, e que só se revela a mim na relação com o outro. Sob esse prisma, o outro ocupa o lugar da revelação daquilo que desconheço em $\mathrm{mim}^{2}$.

No mundo atual o olhar entre pessoas, e entre as pessoas e os objetos, expande-se e beneficia-se através do uso da técnica, pois não somos mais apenas olhados pelo outro, mas por objetos que se comunicam conosco de modo peculiar, exigindo novas maneiras de interlocução e de revelação. Estamos falando, portanto, da máquina fotográfica como uma espécie de máquina de visão, que desencadeia novas maneiras de tomarmos consciência do mundo e de nós mesmos. A experiência proporcionada pela câmara fotográfica amplia o campo da percepção, transformando a habilidade de conhecer o mundo físico e social.

2. Mikail Bakhtin (1985) apresenta o conceito de exotopia para explicitar o fato de uma consciência ver a outra como um todo, o que ela não pode fazer consigo própria. Utilizamos aqui este conceito para introduzir a perspectiva do olhar mediado pelo aparato técnico. 
A produção de imagens fotográficas pelos jovens no contexto escolar é o nosso foco de análise. As fotografias desencadeiam um outro modo de olhar o mundo, enriquecendo as possibilidades de apresentação dos fatos, objetos, pessoas e acontecimentos. A construção de sentido através da imagem se dá na interlocução, num primeiro momento, entre o sujeito e a câmara fotográfica e, posteriormente, no diálogo entre o pesquisador e o jovem fotógrafo, que narra por meio de palavras o sentido das imagens que foram selecionadas no cotidiano e produzidas como fotografias, permitindo que sejam analisadas sob novo ângulo de visão. A próxima etapa será mostrar como isso de fato aconteceu no contexto escolar.

\section{A PROPOSTA E O CONTEXTO}

O trabalho com fotografia desenvolvido na escola tem como objetivo mais amplo facilitar a experiência de educadores e educandos com a produção e fruição de imagens visuais e mobilizar a produção de narrativas. Para atingir esse objetivo são promovidos encontros semanais, com duração de três horas, no espaço de uma escola "especial" do município do Rio de Janeiro. Participam desses encontros duas pesquisadoras, a professora e cinco alunos adolescentes (três meninas e dois meninos) dessa escola e cinco alunas adolescentes da escola regular.

Os alunos que freqüentam a escola "especial" são portadores de diferentes tipos de deficiência e apresentam necessidades especiais de aprendizagem. Nesse grupo, quatro adolescentes sofreram paralisia cerebral e dependem de cadeira de rodas para locomoção, apresentam dificuldades motoras mais severas e limitações em sua expressão oral e escrita; um adolescente apresenta dificuldades na expressão oral e um retardo mental leve. Todos procuram se comunicar de algum modo e exploram de formas diferentes os recursos de linguagem, tais como: emissão de sons com variação de entonação, gesticulação, expressão corporal e facial. O trabaIho com esse grupo requer a atenção constante do professor na interpretação dos diferentes códigos de linguagem que são construídos individualmente pelo aluno, como forma de comunicação e expressão. A parceria entre educador e educando, nesse contexto, é condição primordial e facilitadora do processo de construção de conhecimento, comunicação e integração social.

A criação desse trabalho integrado, no qual participam jovens da escola regular e da escola "especial", veio contribuir para a concretização do projeto políticopedagógico da escola "especial", que visa oferecer a todos os educandos, independentemente de suas características ou limitações, as mesmas condições de acesso e 
construção de conhecimento no espaço escolar. $\bigcirc$ projeto visa construir um espaço de ação educativa, constituído a partir de uma perspectiva inclusiva ${ }^{3}$. A linguagem fotográfica é vista, assim, como mais um recurso pedagógico a ser explorado na busca de alternativas e adaptações curriculares que facilitem o processo de ensino-aprendizagem. Pensando a prática pedagógica sob a ótica da "remoção de barreiras à aprendizagem" (Carvalho, 1998), argumentamos que a fotografia pode ser tomada como uma importante linguagem a ser explorada no processo de construção de conhecimento e narrativas, de busca de sentidos e significados.

Neste texto, destacamos para análise o resultado de uma das atividades propostas ao grupo. Com a intenção de mobilizar um outro olhar sobre a realidade do espaço escolar, no qual estamos diariamente inseridos, criamos a proposta de que cada aluno produzisse uma pequena série de registros fotográficos sobre sua escola. Nossa intenção era tornar visíveis, nas imagens fotográficas, aspectos positivos e negativos que envolvem o cotidiano escolar. Durante alguns dias, cada aluno do grupo integrado ficou com a câmera fotográfica, criando suas fotos durante o período de aulas e dentro de suas respectivas escolas, regular ou "especial".

Após a produção das fotografias, realizamos uma dinâmica na qual os alunos, individualmente, apresentavam suas fotos comentando com o grupo a razão pela qual haviam selecionado e realizado aqueles registros. A dinâmica foi informal e se caracterizou como um diálogo em que todos podiam intervir quando desejassem. Dessa forma, os alunos foram penetrando na fala um dos outros e, ao final, a narrativa construída foi o resultado da experiência do grupo, envolvendo diferentes comentários e pontos de vista sobre aspectos do cotidiano escolar. $\bigcirc$ diálogo produzido pelo grupo a partir da leitura das imagens foi gravado e, posteriormente, transcrito para análise.

Essa proposta de trabalho possibilitou uma outra forma de aproximação da realidade escolar, a partir do olhar e das narrativas construídas pelos próprios alunos. $\bigcirc$ diálogo desencadeado no processo de produção e leitura das fotografias revela características que aproximam e distinguem o contexto das escolas, " especial" e regular, e abre-nos uma perspectiva crítica e sensível de observação e análise sobre a escola, o processo de ensino-aprendizado e de inclusão social.

3. Princípio norteador das ações e políticas educacionais que têm como perspectiva a democratização do acesso de todos os alunos à escola, independentemente de suas condições físicas, intelectuais, sociais, emocionais, lingüísticas ou outras. 


\section{OBSERVAR E NARRAR: O QUE REVELAM AS FOTOGRAFIAS}

A investigação é feita a partir da construção de uma leitura do sentido subjetivo e do conteúdo cultural das imagens fotográficas, produzidas pelos jovens no contexto escolar. Nossa intervenção apresenta-se em dois momentos distintos e complementares. Num primeiro momento, os jovens são solicitados a produzir imagens fotográficas na escola. A solicitação desencadeia um certo modo de observar o espaço escolar, buscando um conteúdo com o qual a foto irá ganhar uma determinada expressividade. Posteriormente, as fotos são apresentadas no grupo e discutidas coletivamente. Com essa estratégia incentiva-se, com as imagens e através delas, a criação de um campo dialógico que amplia o significado original da imagem fotografada, possibilitando que novos sentidos sejam negociados. A partir dessa negociação as imagens ganham interpretações que não estavam previstas pelo autor da foto no exato momento de sua criação. Da imagem à palavra, e da palavra de volta à imagem, ampliam-se não só os modos de observação como as possibilidades de interpretar uma mesma imagem. Na foto o tempo de observação é determinado pelo leitor/observador, que pode inclusive conduzir seu olhar para além do enquadramento dado pelo fotógrafo no momento do clique.

Roland Barthes (1989) destaca a multiplicidade de leituras da imagem fotográfica e o modo como uma imagem anima seu observador. Na relação estabelecida entre a foto e o espectador, dois movimentos se distinguem: da imagem em direção ao observador; do observador em direção à imagem. $\bigcirc$ primeiro movimento, Barthes denomina studium, e assim se refere aos pontos sensíveis, as marcas que partem da foto e atingem o espectador, chamando-lhe a atenção. Reconhecer o "studium é descobrir as intenções do fotógrafo, entrar em harmonia com elas, aproválas, desaprová-las, mas sempre compreendê-las, discuti-las interiormente, pois a cultura é um contrato feito entre criadores e consumidores" (p.48). No segundo movimento, denominado punctum, a reação parte do espectador e leva-o a acrescentar alguma coisa à foto. A imagem fotográfica anima o espectador a ultrapassar o seu próprio enquadramento. Nas palavras de Barthes, "o punctum é, portanto, uma espécie de fora-de-campo subtil, como se a imagem lançasse o desejo para além daquilo que dá a ver" (p. 85). "O punctumé aquilo que eu acrescento à foto e que, no entanto, já lá está" (p. 82). É da tensão entre o studium e o punctum que acontece uma nova leitura da imagem.

Selecionamos para análise oito fotografias tiradas por quatro jovens: Maria e Ivone (alunas da escola regular); Sérgio e Rui (alunos da escola "especial"). Vale ressaltar que na dinâmica de leitura das imagens a participação envolveu todo o 
grupo integrado. Observamos que dessas imagens e do diálogo com os jovens emergem seis temas, os quais analisaremos a seguir.

\section{MURAL: ESPAÇO DE INTERLOCUÇÃO}

A foto número I foi tirada por Maria e mostra um mural no interior da sala. Ela considera que esta foto registra um aspecto positivo da escola. Maria manifesta o seu contentamento em relação ao processo de criação e ao resultado final dos desenhos que foram produzidos em grupo e colocados no mural.

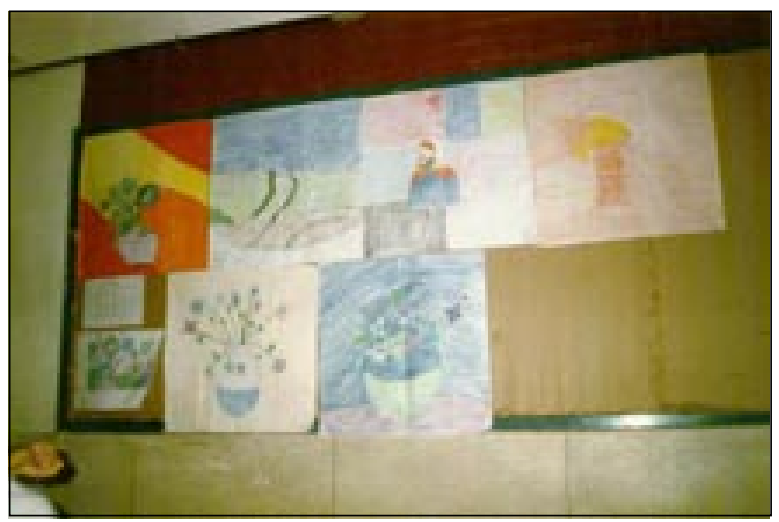

FOTO No I

MARIA: Bom, essa foto aqui eu tirei por causa do trabalho que nós fizemos lá na escola e ficou bem, eu gostei, saiu um resultado bom.

ANA (pesquisadora): Quer dizer que isto aqui é uma coisa que você gosta? Maria: É.

AnA: Em que aula você fez o trabalho?

MARIA: De artes.

ANA: Tem algum trabalho seu aí?

MARIA: Tem, esse aqui...Esse aqui foi em grupo. Foi um resultado bom. Foi um resultado tão bom, que ela colocou no mural.

LucianA (pesquisadora): Você gostou da atividade ou você gosta da aula de artes em geral?

MARIA: Eu gostei da atividade. 
A foto número 2 foi realizada por Ivone. Vale destacar dois momentos distintos: o de produção e o de leitura da imagem. Ivone, quando selecionou este recorte da sala de aula, tinha como intenção fotografar os colegas. Entretanto, no diálogo promovido no grupo, o seu olhar se desloca para uma outra questão, também presente na imagem, mas que não foi o motivo original que a desencadeou. $\bigcirc$ diálogo entre as imagens de Maria e Ivone gerou um novo sentido para a foto, e o que era inicialmente fundo passa a ser o tema principal da foto e desencadeia uma discussão no grupo. Desse modo, durante a apresentação coletiva das fotos no grupo, Ivone destaca o mural e tece comentários sobre seu aspecto degradado. Ela então manifesta o seu descontentamento com esta imagem, dizendo que o mural é constantemente pichado pelos alunos de outra turma. A sua foto, embora não traga em primeiro plano a imagem do mural, retoma este tema, presente também na foto de Maria, trazendo outra perspectiva de análise.

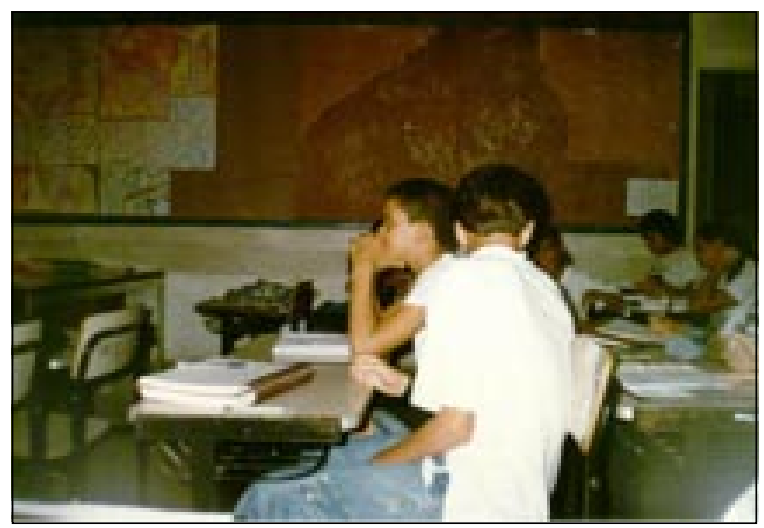

FOTO $N^{\circ} 2$

IVONE: Essa aqui é ruim porque a maioria dos murais de lá tá tudo feio! Até a própria turma da manhã rasga o mural e a sala fica tudo feio. Eles picham e depois botam a culpa na gente.

ANA (pesquisadora): Por que metade está arrumadinho e a outra metade não está? MARIA: Porque na metade eles queriam preservar o trabalho deles e na outra eles aproveitaram e riscaram, picharam...

ANA: Então, quer dizer que eles não picham na parte que tem os trabalhos?

ELIZETE: É, eles fazem isso na parte que não tem trabalho, pra dizer que o pessoal da tarde que rasgou.

ANA: Quando tem trabalho eles respeitam e não picham em cima?

MARIA: Não, pelo menos eles respeitam. 
O mural apresenta-se como lugar de tensão entre os grupos que dividem o mesmo espaço e, às vezes, apresentam posturas diferentes. Os próprios alunos constroem suas críticas, mostrando nas imagens seus diferentes pontos de vista. $\bigcirc$ mural aparece como um lugar de valorização da produção dos alunos, mas também como lugar de contestação. Os jovens estão apontando uma questão que deve ser discutida amplamente e que pode ser retomada para além do objeto mural em si mesmo, ou seja, o tema do mural leva a refletir sobre a ocupação efetiva da escola como espaço de produção de conhecimento, diálogo e interação entre professores, alunos e a comunidade.

\section{IMAGENS DO ENSINAR E APRENDER}

Tanto Maria quanto Ivone escolheram retratar imagens que se referem à aula de geografia. Embora as fotos número 3 e 4 apresentem imagens diferentes, o tema principal é o mesmo. Ivone quer mostrar um professor de que todos gostam muito, e Maria, o ambiente da sala quando este professor está dando aula. Com isso desencadeiam no grupo uma avaliação sobre os professores em geral e o modo como desempenham o papel de mediadores na produção de conhecimento. Ao recortar estas imagens como positivas, os alunos iniciam uma reflexão sobre os critérios que definem um bom e um mau professor, como também uma aula considerada boa e uma aula considerada ruim.

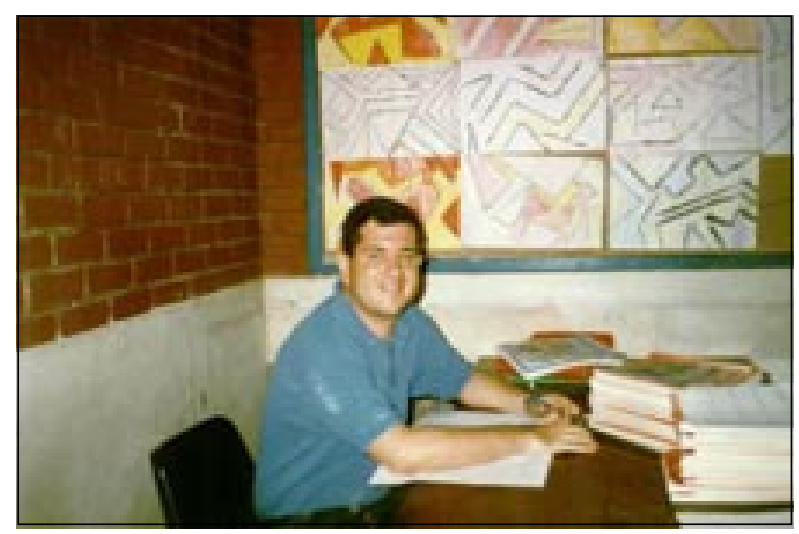

FOTO $\mathbf{N}^{\circ} 3$ 
IVONE: Este aqui é o famoso professor de Geografia. Uma das melhores aulas!!

ANA (pesquisadora): Por que é a melhor?

ELIZETE: Porque ele é calmo...

IVONE: Ele é diferente dos outros professores. É pela pessoa que ele é mesmo. Ele sabe dar aula muito bem! Ele trata os alunos como gente! Não chega dentro da sala descontando os problemas dele.

MARIA: Ele é supercalmo, o negócio dele é conversar, o negócio dele não é dar ordem: senta, é isso, aqui, sabe? O negócio dele é conversar!

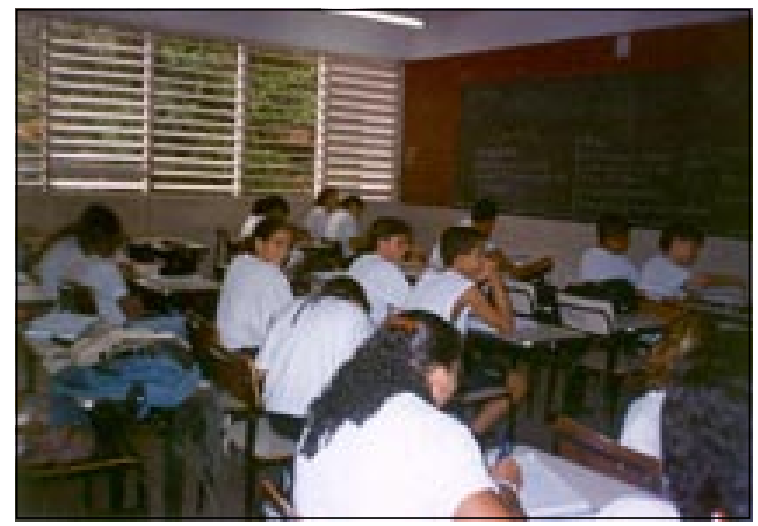

FOTO No 4

MARIA: Essa aqui é na aula de Geografia. É bom. Por causa do professor, da aula, da matéria, por causa de tudo!

IVONE: A aula é bem animada.

MARIA: A aula é bem assim aberta, bem animada.

ANA (pesquisadora): E o pessoal se comporta para aprender?

MARIA: Se comporta, a turma toda respeita ele.

LUCIANA (pesquisadora): Ele conversa com vocês?

MARIA: Conversa qualquer assunto. Ele é bem aberto!

Com as imagens as alunas enfatizam o valor do diálogo, da compreensão e do respeito mútuo, aspectos presentes na relação desse professor com a turma. As alunas falam do professor como alguém que constrói laços afetivos, transmite conhecimentos e desenvolve uma dinâmica de aula que propicia um clima de trabalho produtivo e prazeroso. Se, por um lado, o close do professor traz como referência esses aspectos de uma forma personalizada, a foto dos alunos na aula explicita um 
ponto de vista diferente, porque enfatiza o processo pedagógico. Com essas características, os alunos estão definindo os critérios positivos que deveriam orientar a proposta pedagógica da escola como um todo.

\section{A PROVA}

A foto número 5 foi tirada por Sérgio, aluno da escola "especial". A intenção foi retratar sua professora dando aula. Esta imagem desencadeou uma conversa entre dois alunos, Sérgio e seu colega de turma, Rui. No diálogo, transcrito abaixo, observamos que predomina na leitura realizada por Sérgio uma narrativa basicamente descritiva do que ele identifica na foto. Entretanto, com a mediação do colega, da professora e da pesquisadora, Sérgio começa a interpretar a imagem. Seu olhar dirige-se à prova que está sobre a mesa e ele passa a mostrar o seu ponto de vista sobre esta prática pedagógica. Esta imagem provoca um sentimento ambivalente, porque ela apresenta a professora como alguém de quem eles gostam, mas, também, evoca uma associação com a prova, algo de que Sérgio não gosta porque fica nervoso em situações de avaliação.

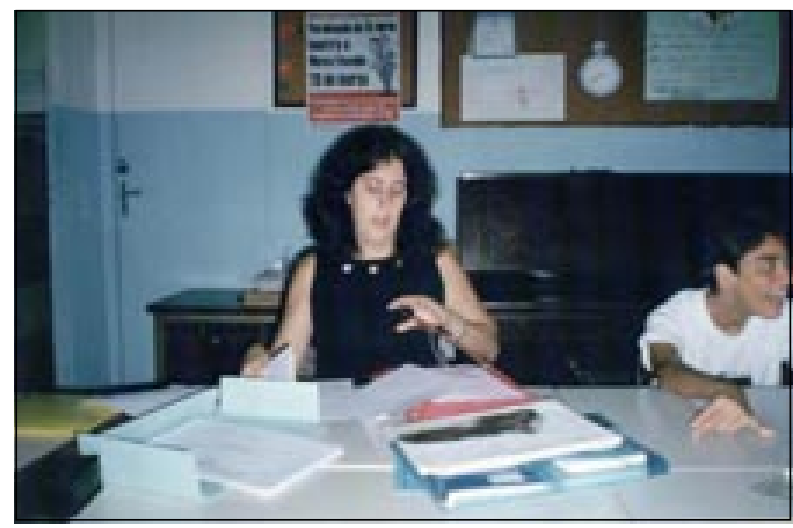

FOTO $N^{\circ} 5$

RuI: A Cláudia e a aula.

ANA (pesquisadora): É uma coisa boa?

RuI: É.

ANA: O que você acha, Sérgio? 
SÉRGIO: Ela está segurando uma pasta.

ANA: Sim, está pegando a pasta.

SérGIO: Para a chamada.

ANA: Mas essa foto é boa ou ruim para você?

SÉRGIO: Ruim...

AnA: Por que?

SÉRGIO: É boa...

Ana: Você gosta da aula?

Rul: Às vezes.

SÉRGIO: Às vezes.

AnA: Às vezes você não gosta?

Rul: É.

ANA: Por quê?

SÉRGIO: A prova.

AnA: Por que você não gosta de prova?

SÉRGIO: É.

PROFESSORA DA TURMA: Tirou dez e não gosta de prova?!

AnA: E você Rui?

Rul: Eu gosto. (risadas)

PROFESSORA DA TURMA FALANDO DO SÉRGIO: Ficou com medo, ficou nervoso...

AnA: Depois mostra a prova pra gente. Tirou dez! Vocês dois?

SÉrgIO E RUI: Sim.

A prova é um instrumento de avaliação que está presente no contexto escolar. Ainda que para essa turma da escola "especial" a prova não seja o instrumento mais importante de avaliação do ponto de vista do professor, ela aparece neste diálogo como algo que os aproxima dos modos de avaliação presentes na escola regular. Apesar das contradições e das limitações da prova como instrumento de avaliação, na visão de Rui, ela ganha uma dimensão positiva, o que não acontece na visão do Sérgio.

\section{MENINOS VERSUS MENINAS: A LINGUAGEM DO ESPAÇO}

A foto número 6 foi tirada por Ivone. Seu objetivo é mostrar a ocupação, pelos meninos, do espaço destinado ao recreio. Outra questão suscitada: divisão, ocupação e controle do espaço pelos alunos. A análise é feita a partir do ponto de vista das meninas. 


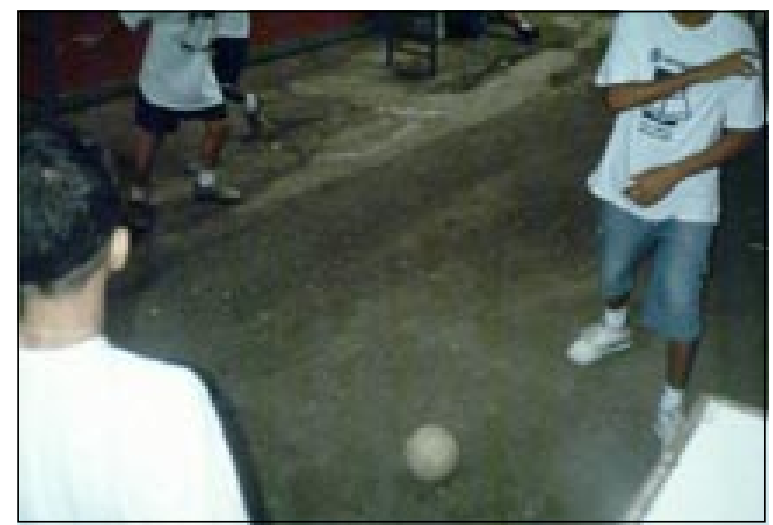

FOTO No 6

ANA (pesquisadora): E esta foto aqui?

IVONE: É lá onde tem o único espaço grande e os meninos ocupam!

MARIA: Aqui está mostrando eles jogando bola. Tá vendo, só menino! Eu e ela (Ivone) ficamos lá perturbando eles.

IVONE: Aonde a gente fica sentada, a bola vem pro nosso lado e a gente chuta pro outro lado. Eles ficam bolados!! (risadas)

IVONE: A maioria dos meninos ficam jogando bola, tropeçam, eles caem pra caramba! A maioria cai porque a gente derruba, né?

MARIA: O recreio é totalmente só dos meninos.

IVONE: É claro, só os meninos que jogam...Teve um dia que a gente jogou. Teve um dia que eu e ela fomos as goleiras. Foi legal, nós ficamos jogando com eles. Nós ficamos de goleiras e eles respeitaram a gente. Mandaram bolinha fraca pra gente.

Essa discussão entre as meninas traz uma questão social que remete à reflexão sobre o lugar ocupado pela mulher na sociedade e as transformações que começam a despontar. As meninas mostram que o espaço se organiza ainda sob a ótica e o controle masculino, porém, não se submetem passivamente a essa situação. Criam momentos de tensão que colocam em evidência um olhar crítico sobre esta realidade e, ao mesmo tempo, reivindicam uma mudança de postura.

\section{O ESPAÇO E SUAS BARREIRAS}

A seguir temos a foto número 7, tirada pelo Rui, aluno que depende de cadeira de rodas para locomoção. Ele retratou uma passagem muito utilizada pelos alunos porque liga as salas de aula ao refeitório. Ele apresenta esta foto como uma imagem 
negativa e com ela encaminha uma reivindicação. No diálogo com os alunos ela desencadeou uma crítica em relação às barreiras arquitetônicas que limitam, dificultam ou impedem a locomoção independente dos portadores de deficiência física.

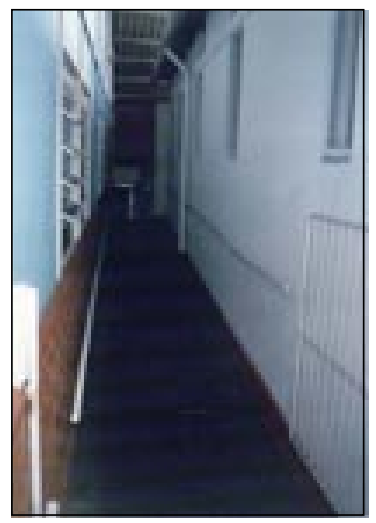

FOTO $N^{\circ} 7$

RuI (apontando a foto do corredor da escola): É ruim... é muito inclinada... Parece que vai cair.

MARIÂNGELA (aluna de escola regular): É ruim porque tem que inclinar a cadeira pra subir, né Rui?

RUI: É.

ANA (pesquisadora): É muito inclinado e você se sente mal na cadeira quando alguém te empurra. A inclinação da rampa é muito íngreme?

PROFESSORA Ana LúCIA: E também não dá pra ele sair de lá sozinho, né Rui?

Rul: É.

ANA: Ah, isso é um problema.

Rul: Eu não consigo descer. É ruim.

ANA: É perigoso?

MARIÂNGELA: A cadeira pode capotar e ele cair.

ANA RosA (escolheu também a foto do corredor com a rampa): É ruim! É alto...

ANA (pesquisadora): E na hora que a gente empurra dá medo?

ANA Rosa: É.

MARIÂNGELA (aluna da escola regular): E na hora de subir e de sair da rampa tem que inclinar a cadeira...

ANA: Vamos ver se dá pra consertar isso...

MARIÂNGELA: Tem que abaixar ali um pouquinho... 
Os comentários que surgem a partir da foto do Rui ampliam a compreensão sobre as diferentes formas de nos relacionarmos com o espaço, nas suas particularidades, e conduzem a pensar o mundo físico a partir de outras referências, redimensionando o lugar e o modo como o ocupamos, levando em consideração o ponto de vista do outro.

\section{CONTROLE VERSUS LIBERDADE: DUAS LEITURAS PARA UMA IMAGEM}

A autora da foto número 8 é Ivone. Ela quis mostrar o vendedor de doces. Entretanto, no diálogo com os alunos a imagem foi retomada com outro sentido, e o enfoque passa a ser as grades e a sensação de aprisionamento no espaço escolar. Esta imagem traz a ambivalência do prazer e do desprazer, da liberdade e do aprisionamento vividos na escola.

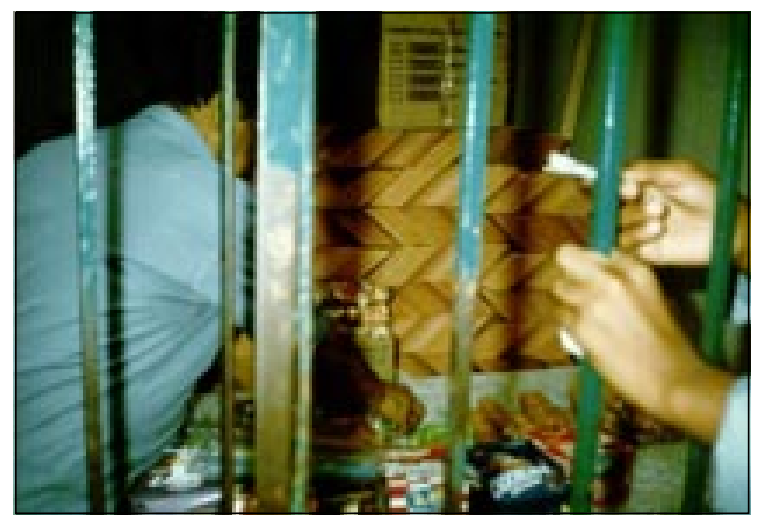

FOTO $N^{\circ} 8$

IVONE: Esta aqui é uma das melhores horas que tem no recreio. Porque a única coisa boa que tem no recreio é o senhor que fica lá vendendo doce. Porque o resto do recreio não tem pra aproveitar porque não tem nada pra fazer. Só os meninos que podem ficar jogando futebol e as meninas não podem fazer nada.

MARIÂNGELA: O muro tá um pouquinho maior que o Sérgio! Parece a Febem ${ }^{4} . .$.

4. Instituição denominada Fundação Estadual do Bem-Estar do Menor e que funcionava como internato para crianças abandonadas e infratoras. Essa instituição foi extinta, porém, a sua representação cultural como presídio para menores ainda permanece forte no imaginário social. 
ANA (pesquisadora): Por que você disse que parece com a Febem?

MARIÂNGELA: Porque parece com a Febem mesmo, tudo arrodiado de muro e grade!

Lá em cima eu acho que também tem grade...

ANA: É pra não deixar ninguém entrar ou sair?

MARIÂNGELA: Pra não deixar sair...

Uma mesma imagem evoca simultaneamente aspectos positivos e negativos e diferentes leituras. A relação com o que é visto como prazeroso e desejável está do lado de fora da escola. $O$ acesso se dá através das grades. Mas as grades também são metáforas visuais de uma experiência de aprisionamento. Que espaço é este e que relações se estabelecem na escola? As imagens, uma vez mais, falam e provocam uma discussão sobre as formas de controle no contexto da escola.

\section{CONSIDERAÇÕES FINAIS}

O objetivo dessa pesquisa-intervenção foi propiciar não apenas uma base técnica preliminar, ensinando ao aluno o manuseio da câmara e as possibilidades que o instrumento oferece, mas, sobretudo, destacar as conseqüências geradas na consciência do sujeito (alunos e professores) a partir da experiência de produção de imagens fotográficas no contexto escolar. Portanto, o mais importante aqui é despertar uma consciência crítica, tanto nas crianças como nos professores, evidenciando o modo como os instrumentos técnicos disponíveis na nossa cultura exercem a função de vetores da subjetividade. Assim sendo, estimular o desenvolvimento mais consciente do ato fotográfico, superando o gesto automatizado que, na maioria das vezes, orienta a ação do registro com a câmara fotográfica, é um primeiro aspecto da proposta. $\bigcirc$ outro aspecto é utilizar a fotografia para construir narrativas que podem levar a reverter a experiência do olhar, enfrentando de modo crítico a banalização da experiência visual no mundo contemporâneo. A foto, como meio de expressão, não deve se limitar ou ficar aprisionada aos sentidos estipulados pela informação massificada. Portanto, consideramos que a pesquisa pode encontrar na fotografia uma forte aliada metodológica para a construção de um olhar crítico sobre o cotidiano. Além disso, o uso da fotografia no contexto escolar justifica-se pela possibilidade de criar estratégias pedagógicas que viabilizem o processo de produção de novas formas de expressão do conhecimento e da crítica da cultura. $\bigcirc$ desafio maior é a criação de espaços de interlocução em que os sujeitos possam experimentar-se, não apenas como sujeitos captados pela lente da câmara, mas, também, como participantes da construção de suas próprias imagens. Essa propos- 
ta de pesquisa pretende assumir um compromisso ético com a nossa época, qual seja, o de manter viva a sensibilidade do olhar perante a própria vida e o mundo.

\section{REFERÊNCIAS BIBLIOGRÁFICAS}

BAKHTIN, M. Estética de la creación verbal. México: Siglo Veintiuno editores, 1985.

BARTHES, R. A câmara clara. Lisboa: Edições 70, 1989.

BENJAMIN, W. Obras escolhidas. São Paulo: Brasiliense, 1996. v. I. Pequena história da fotografia.

CARVALHO, R. E. Temas em educação especial. Rio de Janeiro: WVA, 1998.

FLUSSER, V. Ensaio sobre a fotografia: para uma filosofia da técnica. Lisboa: Relógio D'água, 1998.

JOLY, M. Introdução à análise da imagem. Campinas: Papirus, 1996.

LOPES, A. E.; SANDER, L.; SOUZA, S. J. A Criação de narrativas na escola: uma abordagem através da fotografia. In: PAIVA, A. et al. No fim do século: a diversidade. O Jogo do livro infantil e juvenil. Belo Horizonte: Autêntica, 2000. p. 135-160.

MACHADO, A. Apresentação. In: FLUSSER, V. Ensaio sobre a fotografia: para uma filosofia da técnica. Lisboa: Relógio D'água, 1998. p. 9-22.

MOREIRA, M. L. Retratos de familia: análise da fotografia histórica. São Paulo: Edusp, 1993.

SAMAIN, E. (org.). O Fotográfico. São Paulo: Hucitec, 1998.

SANDER, L. B. Oficina do olhar: metáforas da subjetividade na fotografia. Rio de Janeiro, 2002. Dissert. (mestr.) Departamento de Psicologia da PUC.

SOUZA, S. J. (org.). Mosaico: imagens do conhecimento. Rio de Janeiro: Rios Ambiciosos, 2000.

SOUZA, S. J.; FARAH NETO, M. A Tirania da imagem na educação. Presença Pedagógica, v. 4, n. 22, jul./ago. 1998. 